SUSTAINABILITY

\section{Satellite images show China going green}

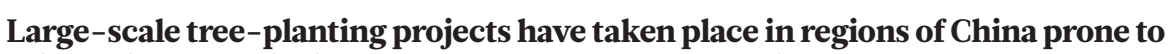

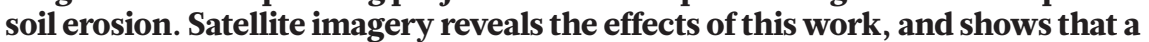
predicted vegetation decline didn't occur during a period of drought.

\section{MARC MACIAS-FAURIA}

$\mathrm{T}$ The effects of human activities on Earth's vegetation have tended to be negative, toration efforts are often restricted to small, localized scales. Large ecological-engineering projects aimed at producing regional-scale effects are few, and among these, China's megaprojects - most notably, the Grain for Green Project $(\mathrm{GGP})^{2}$ - stand out because of their unparalleled massive scale (27.8 million hectares of forest re-established as of 2013 across 26 Chinese provinces $^{3}$ ). Writing in Nature Sustainability, Tong et al. ${ }^{4}$ report that the positive effects of these tree-planting projects remote-sensing satellite imagery of a large region of southwestern China (the provinces of Guizhou, Guangxi and Yunnan), in an area associated with highly erodible landscapes called karst. The authors note that these projects, which require considerable investment, will be justified only if the modification of ecosystem properties can be achieved on a large scale.

The government-run GGP, intended to halt soil erosion and desertification, began in 1999 on mountainous terrain prone to erosion (cropland or scrubland) into forested landscapes (Fig. 1). Such forest would be classified as ecological if trees might eventually be logged (suband as economical if it contained orchards or plantations of trees for medical use. Ecological forest accounted for $80 \%$ of the planting area, with economical forest making up the remaining 20\% (ref. 4). The GGP was developed partly in response to the consequences of land-use changes during the time of Chairman Mao Zedong, notably the huge areas logged to provide fuel and construction materials during the Great Leap Forward programme, and largescale conversions of often marginal, sloping land to agricultural use in the 1960s and 1970s to enhance local self-sufficiency - a change that caused severe erosion problems ${ }^{5}$. mostly because of deforestation ${ }^{1}$. Reson vegetation growth can be detected using (ref. 2). The project's goal was to convert land ject to permission) as part of a timber quota,
To assess the effects of the tree-planting projects, Tong and colleagues use three independent lines of evidence, and the consistency of the findings convincingly support the robustness of their results. One approach was the analysis of two complementary properties of vegetation. Satellite-imaging data from 1982 to 2015 allowed the researchers to measure the area of vegetation cover present per square metre of ground (known as the leaf-area index). Other satellite data collected between 1992 and 2012 enabled the authors to assess plant biomass in units of aboveground carbon biomass. Plant biomass can be inferred by converting vegetation optical depth (a property captured by microwave observations that are sensitive to the water content of vegetation) to total carbon using an approach based on the carbon density of above-ground, living woody vegetation.
Over time, both of these properties revealed a marked transition in the amplitude and/or direction of vegetation trends around the main implementation period of the tree-planting project, between 2000 and 2006. The authors' calculations indicate that the southwestern region of China that they studied acted as a carbon sink after the GGP implementation, providing a considerable amount of the entire country's net carbon sequestration. The authors also observed negative vegetation trends in the provinces' growing urban areas, such as in the cities of Kunming and Nanning. This provides an indirect validation of the team's satellite-data approach.

The second line of investigation taken by Tong et al. involved the use of dynamic ecosystem modelling to explore what might have happened in the absence of the tree-planting project. The model took into account the effect of the increase in atmospheric carbon dioxide on vegetation during the time frame studied. This modelling exercise highlighted the divergence between the simulated trend of vegetation decrease projected if the tree-planting intervention had not occurred - linked to a long-lasting drought during the previous decade - and the vegetation increase that was observed.

The third approach taken by the researchers was an analysis of the number of hectares on which tree-planting actions were implemented in each of the 295 counties within the 3 provinces studied. These GGP-inventory data

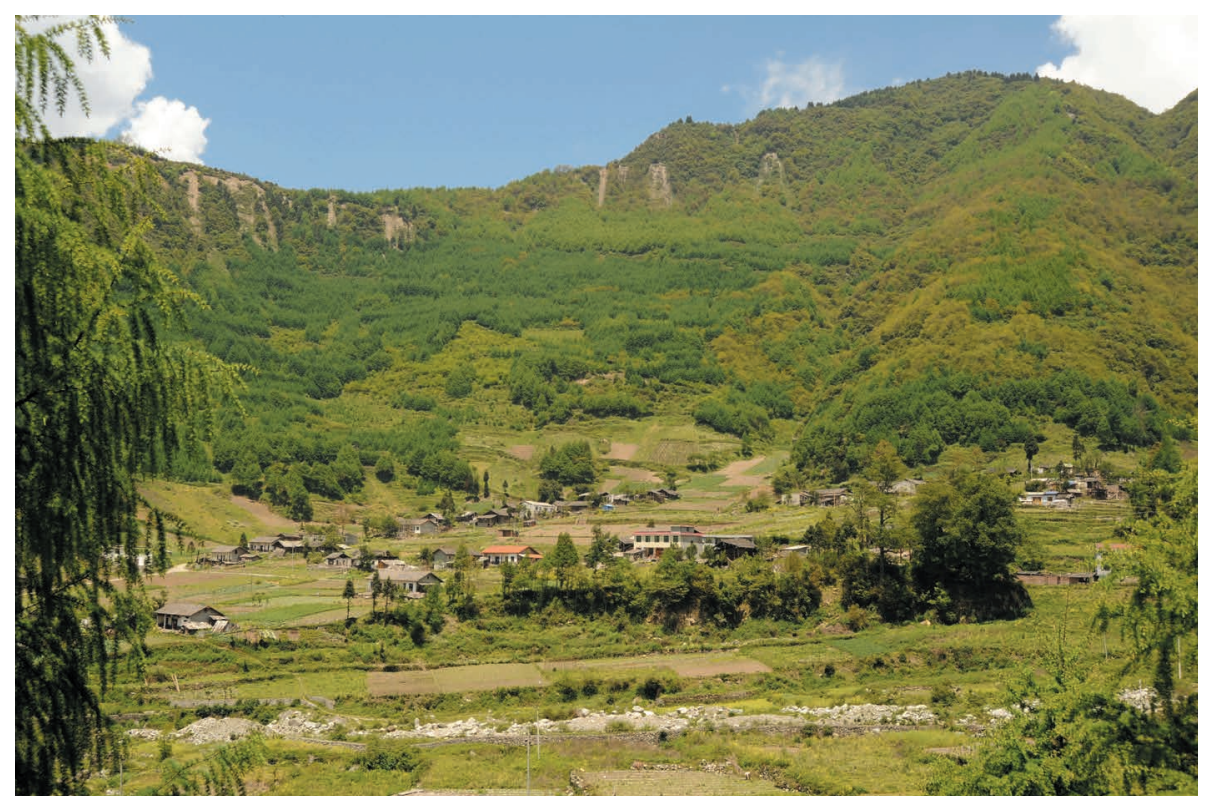

Figure 1 | Trees planted as part of an ecological-engineering project in China. Tong et al. ${ }^{4}$ report an analysis of the effects of a large-scale tree-planting project, called the Grain for Green Project, on mountainous regions of southwestern China that are associated with high levels of soil erosion. Shown here are some trees planted as part of this project in the Wolong Nature Reserve in the southwestern Sichuan province. 
showed a correspondence between actions at the county level and positive vegetation trends, as well as stark differences between China's provinces and the neighbouring countries of Laos, Vietnam and Myanmar, in which the vegetation assessed by satellite imagery decreased over the same period.

Tong and colleagues' results are encouraging in regard to the large-scale effects of the GGP on vegetation, but should not be taken as a proof of its overall success. As the authors mention, the satellite trends were not validated by measurements taken on the ground. No erosion assessment was undertaken, so one of the main GGP goals was not evaluated directly. Furthermore, the time span of satellite analysis, and of the programme itself, might still preclude the detection of long-term dynamics related to the long lifespan of trees, or might not take into account the role of large but infrequent erosion or disturbance events such as those linked to torrential rains or pest outbreaks.

Most crucial for the overall assessment of the success of the GGP as an ecological restoration project is the fact that satellite data do not distinguish biological composition, such as the presence of different species, and so cannot be used to assess the project's effects on biodiversity. The GGP focused on the planting of non-native, fast-growing monocultures, which might render the resulting forests more vulnerable to pests ${ }^{3,4}$. The GGP thus used a narrow view of ecosystem services (the role of vegetation in reducing erosion and desertification rates) that had the additional (and possibly unplanned) benefit of a net carbon-storage outcome. Furthermore, the rationale for GGP actions was based not on pre vious ecological states or projected overall ecological benefits, but on the potential to reduce the erosion rates on the target land and for the programme to generate income for farmers ${ }^{2}$.

In the absence of a China-wide assessment of the GGP's environmental and ecological impacts $^{2}$, an analysis of data from China based on 258 publications ${ }^{3}$ identified limited biodiversity benefits of the GGP. This was mainly because the dominant non-native, fastgrowing monoculture plantations were linked to a decrease in floral diversity, associated with bee and bird population declines, as observed in Sichuan province. This report ${ }^{3}$ strongly recommends using native trees when establishing plantations, or at least the establishment of plantations composed of several tree species. Nevertheless, Tong and colleagues' work clearly shows a large-scale effect of the GGP on vegetation in southwestern China. This important result needs to be complemented by ground-based studies. Understanding of the GGP's functional and biodiversity effects is needed to assess its success, and might also identify other interventions that have the potential to enhance or generate wider positive effects of the GGP as an ecological-restoration mega-project. The task set out by Tong and colleagues for how the effects of such massive initiatives can be tested on an adequate scale is valuable and very welcome.

Marc Macias-Fauria is at the School of Geography and the Environment, University of Oxford, Oxford OX1 3QY, UK.

e-mail:marc.maciasfauria@ouce.ox.ac.uk

1. Baccini, A. et al. Science 358, 230-234 (2017)

2. Delang, C. O. \& Yuan, Z. China's Grain for Green Program: A Review of the Largest Ecological Restoration and Rural Development Program in the World (Springer, 2015).

3 Hua, F. et al. Nature Commun. 7, 12717 (2016).

4 Tong, X. et al. Nature Sustain. 1, 44-50 (2018).

5 Harkness, J. China Q. 156, 911-934 (1998). 